\title{
Assessment and effect of a gap between new-onset epilepsy diagnosis and treatment in the US
}

Linda Kalilani, PhD, Edward Faught, MD, Hyunmi Kim, MD, PhD, MPH, Chakkarin Burudpakdee, PharmD, Arpamas Seetasith, PhD, Scott Laranjo, MBA, David Friesen, BSc, Kathrin Haeffs, PhD, Victor Kiri, PhD, MPH, and David J. Thurman, MD, MPH

Neurology ${ }^{\circledR}$ 2019;92:e2197-e2208. doi:10.1212/WNL.0000000000007448

\section{Abstract}

\section{Objective}

To estimate the treatment gap between a new epilepsy diagnosis and antiepileptic drug (AED) initiation in the United States.

\section{Methods}

Retrospective claims-based cohort study using Truven Health MarketScan databases (commercial and supplemental Medicare, calendar years 2010-2015; Medicaid, 2010-2014) and a validation study using PharMetrics Plus Database linked to LRx claims database (2009-2014). Persons met epilepsy diagnostic criteria, had an index date (first epilepsy diagnosis) with a preceding 2 -year baseline ( 1 year for persons aged 1 to $<2$ years; none for persons $<1$ year), and continuous medical and pharmacy enrollment without epilepsy/seizure diagnosis or AED prescription during baseline. Outcomes included percentage of untreated persons (no AED prescription) up to 3 years' follow-up and comparative outcomes (incidence rate ratio: untreated persons/treated persons), including medical events and health care resource utilization.

\section{Results}

In the primary study, 59,970 persons met selection (or inclusion) criteria; $36.7 \%$ of persons with newly diagnosed epilepsy remained untreated up to 3 years after diagnosis. In the validation study $(\mathrm{N}=30,890), 31.8 \%$ of persons remained untreated up to 3 years after diagnosis. Lack of AED treatment was associated with an adjusted incidence rate ratio (95\% confidence interval) of $1.2(1.2-1.3)$ for medical events, $2.3(2.2-2.3)$ for hospitalizations, and 2.8 (2.7-2.9) for emergency department visits.

\section{Conclusions}

One-third of newly diagnosed persons remain untreated up to 3 years after epilepsy diagnosis. The increased risk of medical events and health care utilization highlights the consequences of delayed treatment after epilepsy diagnosis, which might be preventable.

\author{
Correspondence \\ Dr. Kalilani \\ linda.kalilani@ucb.com
}

\section{RELATED ARTICLE}

\section{Editorial}

Undertreatment of newly diagnosed epilepsy in the US: Mind the gap!

Page 879 


\section{Glossary}

AED = antiepileptic drug; $\mathbf{C C M C}=$ Truven Health MarketScan database Commercial Claims; $\mathbf{C I}=$ confidence interval; ED = emergency department; HIPAA = Health Insurance Portability and Accountability Act; ICD-9-CM = International Classification of Diseases, Ninth Revision, Clinical Modification; IRR = incidence/event rate ratio; LRx = Longitudinal Prescription Database; MDCD = Truven Health MarketScan Multi-State Medicaid databases; MDCR = Truven Health MarketScan Medicare Supplemental and Coordination of Benefits (Medicare Supplemental).

Epilepsy adversely affects the physical, mental, and social wellbeing of persons ${ }^{1,2}$ and is associated with a 2 to 3 times greater mortality rate compared with the general population., Practice guidelines recommend prompt treatment with an antiepileptic drug (AED) following a confirmed diagnosis of epilepsy. ${ }^{5}$ Untreated persons with epilepsy may experience higher complication rates such as recurring seizures and a reduced quality of life. ${ }^{1,6,7}$ However, studies have found that some persons with epilepsy who should receive AED treatment remain untreated, that is, there is a "treatment gap." 8,9 Use of AEDs varies by geographical location, with suboptimal use reported more frequently in low- and middle-income countries compared with high-income countries, and particularly in rural areas. ${ }^{9-11}$ Factors contributing to the treatment gap include lack of trained clinicians to diagnose and treat persons, cost of treatment, unavailability of medication, distance to health care services, and cultural beliefs. ${ }^{12-14}$

Most studies on the epilepsy treatment gap have been conducted in low-income nations and have reported treatment gaps up to $95 \% .^{9}$ Few studies have evaluated an epilepsy treatment gap in high-income nations. Data on an epilepsy treatment gap in the United States (US) are derived mainly from national surveys that used self-report measures. For example, the Behavioral Risk Factor Surveillance Survey conducted in 2005 found that $51.2 \%$ (95\% confidence interval [CI]: $46.4 \%-55.9 \%)$ of adults with a history of epilepsy, $6.9 \%$ (95\% CI: 4.9\%-9.7\%) with active epilepsy, and 16.1\% (95\% CI: $11.3 \%-22.4 \%$ ) with a recent seizure reported not taking any medication to control a seizure disorder or epilepsy. ${ }^{15}$ Identifying a gap in epilepsy treatment and associated factors will help inform strategies to improve both access to care and quality of life. The purpose of our study was to estimate the treatment gap among newly diagnosed persons with epilepsy in the US and to assess the effect of lack of treatment on health outcomes.

\section{Methods}

\section{Data sources}

This was a retrospective cohort study that was conducted using multiple databases. The study period for each database was defined based on the most recent data that were available at the time the study was conducted. Initially, the study was conducted in the Truven Health MarketScan database Commercial Claims (CCMC [EV] 2015 v0.4), the Truven Health MarketScan Medicare Supplemental and Coordination of
Benefits (Medicare Supplemental) (MDCR [EV] 2015 v0.4) databases covering the period January 1, 2010, to December 31, 2015, and the Truven Health MarketScan Multi-State Medicaid databases (MDCD $2014 \mathrm{v} 1.0$ ) covering the period January 1, 2010, to December 31, 2014. The CCMC database consists of data from commercially insured individuals (i.e., working age adults and their dependents), while the MDCR database consists of data from individuals with Medicare coverage (a US federal health insurance program for older or disabled persons) plus employer-paid commercial plans. The MDCD consists of data from individuals with limited incomes whose insurance is paid by the state. These databases contain information on medical treatment (inpatient, outpatient, and emergency care), pharmacy claims information, and enrollment history.

A follow-up validation study was conducted in the IQVIA PharMetrics Plus Database covering the period from January 1, 2009, to December 31, 2014, which was linked to the IQVIA Longitudinal Prescription Database (LRx) covering the same period. The PharMetrics Plus database consists of adjudicated claims for more than 150 million unique persons, mainly commercially insured individuals. The database contains information on medical treatment (inpatient, outpatient, and emergency care), retail and mail order prescription records information, and enrollment history. The LRx database consists of deidentified information on prescriptions sourced from retail, mail, long-term care, and specialty pharmacies, representing $92 \%$ of total retail pharmacy prescriptions and $62 \%$ of prescriptions dispensed in the mail channel in the US (IQVIA data on file).

The PharMetrics Plus database consists mostly of commercially insured persons with a small subset of managed Medicare persons. The Truven Health MarketScan database consists of data from persons covered under Medicaid, in addition to commercially insured persons. The validation study was conducted with the PharMetrics Plus database because of the ability to link to the LRx database to obtain as much information as possible on AED prescriptions. Both databases are compliant with the Health Insurance Portability and Accountability Act (HIPAA) of 1996, and all data were deidentified.

\section{Study population}

The study included persons newly diagnosed with epilepsy. The index date was defined as the date of the first diagnosis of epilepsy with a preceding 2-year baseline period (1 year for 
persons aged 1 to $<2$ years; none for persons $<1$ year). Persons were required to have continuous medical and pharmacy enrollment without an epilepsy or seizure diagnosis or AED prescription during the baseline period, and to meet epilepsy diagnosis criteria (defined below) on the index date.

Epilepsy diagnosis required any of the following criteria:

1. Two ICD-9-CM 345.xx (epilepsy and recurrent seizures) codes at separate encounters (separate dates in any care setting). The accuracy for identifying persons with epilepsy using at least 2 ICD-9 codes for epilepsy is $90 \%{ }^{16}$

2. One ICD-9-CM 345.xx (epilepsy and recurrent seizures) code and 1 ICD-9-CM 780.39 (other convulsions) code among separate encounters (separate dates in any care setting). Persons with only 780.39 (other convulsions) codes were excluded in an effort to omit persons with acute symptomatic seizures but not epilepsy. The accuracy for identifying persons with epilepsy using at least 2 ICD-9 codes for epilepsy is $90 \%{ }^{16}$

3. Persons with the ICD-9-CM code 345.3 (grand mal status) were required to have 2 ICD-9-CM 345.3 (grand mal status) codes separated by at least 30 days, or an ICD-9-CM 345.3 (grand mal status) code and 1 ICD-9-CM 780.39 (other convulsions) code separated by at least 30 days, or 1 ICD-9-CM code 345.3 (grand mal status) and 1 ICD-9-CM (epilepsy and recurrent seizures) 345.xx code encounters on separate days. The accuracy for identifying persons with epilepsy using at least 2 ICD-9 codes for epilepsy is $90 \%{ }^{16}$

Seizure types were defined as focal (1 ICD-9-CM codes $345.4 \mathrm{x}, 345.5 \mathrm{x}$, or 345.7x and no occurrences of ICD-9-CM codes 345.0x, 345.1x, or 345.2); generalized (1 ICD-9-CM codes 345.0x, 345.1x, or 345.2x and no occurrences of ICD-9CM codes $345.4 \mathrm{x}, 345.5 \mathrm{x}$, or $345.7 \mathrm{x}$ ); or undefined (all other cases, including epilepsy/seizure codes that were nonspecific as to focality [ICD-9-CM codes 345.3x, 345.6x, 345.8x, $345.9 x$, or 780.39 ] as well as inconsistent codes [some indicating focal and others indicating generalized]).

To estimate the proportion of treated persons, follow-up began with the individual's initial epilepsy diagnosis and continued to either the end of the study period, end of enrollment in the insurance plan, or the first record of a prescription of an AED. Persons were considered treated if they had a prescription of an AED (at least a 30-day supply) at any time during the follow-up period. Untreated persons had no record of any pharmacy claim for an AED during the entire follow-up period but had claims records for inpatient, outpatient, or pharmacy claims for other medications.

Sensitivity analyses were conducted to assess the rigor of the case definition of epilepsy and the probability of receiving AED treatment by increasing the number of ICD-9 codes of epilepsy required to qualify as having an epilepsy diagnosis, the minimum time required between the epilepsy ICD-9 diagnosis codes, and the location of the epilepsy ICD-9 codes on the diagnosis list (principal diagnosis vs all fields), as indicated in table 1 . Additional sensitivity analyses were conducted to assess whether AED treatment following an epilepsy diagnosis was affected by factors of the person's demographic characteristics, the presence of medical conditions whose presentation may be confused with epilepsy (e.g., syncope), or the health care setting or clinician providing the diagnosis.

Comparisons of health outcomes, including incidence or event rates of selected medical events often associated with

Table 1 Case definition of epilepsy

\begin{tabular}{|c|c|}
\hline $\begin{array}{l}\text { Study } \\
\text { population }\end{array}$ & Case definition of epilepsy \\
\hline $\begin{array}{l}\text { Primary case } \\
\text { definition }\end{array}$ & $\begin{array}{l}\text { An occurrence of } \geq 2 \text { ICD-9-CM codes }{ }^{a} \text { of } 345 . x x \text { among } \\
\text { separate medical encounters (separate dates in any } \\
\text { care venue); an occurrence of } \geq 1 \text { ICD-9-CM code of } \\
345 . x x \text { and } \geq 1 \text { ICD-9-CM code of } 780.39 \text { among } \\
\text { separate medical encounters; persons with ICD-9-CM } \\
\text { code } 345.3 \text { will be required to have an occurrence of } \\
\geq 2 \text { ICD-9-CM codes of } 345.3 \text { separated by at least } 30 \text { d } \\
\text { or an occurrence of the } 345.3 \text { code and } \geq 1 \text { ICD-9-CM } \\
\text { code } 780.39 \text { separated by at least } 30 \mathrm{~d} \text {, or } \geq 1 \text { ICD-9-CM } \\
\text { code } 345.3 \text { and } \geq 1 \text { ICD-9-CM code } 345 . x x \text { encounters } \\
\text { on separate days }\end{array}$ \\
\hline
\end{tabular}

No. of ICD-9-CM codes of 345.xx as separate
encounters (by at least $1 \mathrm{~d}$ )

\begin{tabular}{|c|c|}
\hline Case definition 1 & $\geq 2$ \\
\hline Case definition 2 & $\geq 3$ \\
\hline \multirow[t]{2}{*}{ Case definition 3} & $\geq 4$ \\
\hline & $\begin{array}{l}\text { No. of ICD-9-CM codes of } 345 . x x \text { as separate } \\
\text { encounters (by at least } 30 \mathrm{~d} \text { ) }\end{array}$ \\
\hline Case definition 4 & $\geq 2$ \\
\hline Case definition 5 & $\geq 3$ \\
\hline \multirow[t]{2}{*}{ Case definition 6} & $\geq 4$ \\
\hline & $\begin{array}{l}\text { No. of ICD-9-CM codes of } 345 . x x \text { as separate } \\
\text { encounters (by at least } 1 \mathrm{~d} \text { ). Only selecting epilepsy } \\
\text { codes that were codes as the principal/first diagnosis }\end{array}$ \\
\hline Case definition 7 & $\geq 2$ \\
\hline Case definition 8 & $\geq 3$ \\
\hline \multirow[t]{2}{*}{ Case definition 9} & $\geq 4$ \\
\hline & $\begin{array}{l}\text { No. of ICD-9-CM codes of } 345 . x x \text { as separate } \\
\text { encounters (by at least } 30 \mathrm{~d} \text { ). Only selecting epilepsy } \\
\text { codes that were codes as the principal/first diagnosis }\end{array}$ \\
\hline $\begin{array}{l}\text { Case definition } \\
10\end{array}$ & $\geq 2$ \\
\hline $\begin{array}{l}\text { Case definition } \\
11\end{array}$ & $\geq 3$ \\
\hline $\begin{array}{l}\text { Case definition } \\
12\end{array}$ & $\geq 4$ \\
\hline
\end{tabular}

Abbreviation: ICD-9-CM = International Classification of Diseases, Ninth Revision, Clinical Modification.

a 345. $x x=$ epilepsy and recurrent seizures; 345.3 = grand mal status; 780.39 $=$ other convulsions. 
Table 2 Baseline characteristics of the study population in the Truven Health MarketScan database

\begin{tabular}{|c|c|}
\hline Characteristic & $\begin{array}{l}\text { All persons } \\
(N=59,970)\end{array}$ \\
\hline Age, $y$, mean \pm SD & $35.0 \pm 27.3$ \\
\hline \multicolumn{2}{|l|}{ Age, y, n (\%) } \\
\hline $0-4$ & $7,935(13.2)$ \\
\hline $5-14$ & $11,253(18.8)$ \\
\hline $15-24$ & $9,239(15.4)$ \\
\hline $25-44$ & $8,173(13.6)$ \\
\hline $45-64$ & $12,928(21.6)$ \\
\hline $65+$ & $10,442(17.4)$ \\
\hline \multicolumn{2}{|l|}{ Sex, n (\%) } \\
\hline Female & $30,292(50.5)$ \\
\hline Male & $29,678(49.5)$ \\
\hline \multicolumn{2}{|l|}{ Geographic region, $n$ (\%) } \\
\hline Northeast & $8,030(13.4)$ \\
\hline North Central & $12,009(20.0)$ \\
\hline South & $16,844(28.1)$ \\
\hline West & $8,481(14.1)$ \\
\hline Other or unknown & $550(0.9)$ \\
\hline Missing & $14,056(23.4)$ \\
\hline \multicolumn{2}{|l|}{ Payer type, n (\%) } \\
\hline Commercial/Medicare & $45,914(76.6)$ \\
\hline Age $<17$ y & $11,774(25.6)$ \\
\hline Medicaid & $14,056(23.4)$ \\
\hline Age $<17$ y & $9,692(69.0)$ \\
\hline
\end{tabular}

epilepsy (falls, fractures, motor vehicle accidents, suicidality, and burns) and health care utilization (inpatient and emergency department [ED] visits), in treated vs untreated persons with epilepsy were also conducted. Persons were considered as having the medical event if they had at least 1 inpatient or 2 outpatient claims (as separate encounters within 7 days) with the diagnoses of interest indicated in any field of diagnosis defined as follows: falls (E880.x-E885.x, E887, and E888.x), fractures (800.xx-801.xx, 803.xx-804.xx, 850.xx-854.xx, 805.xx-829.xx, E887.x, v66.4), motor vehicle accidents (E810.x-E819.x), burns (E891.3, E893.x, E895.xE899.x, 940.xx-949.xx), and suicidality (E950.xx-E958.xx). Events starting in the baseline period and continuing into the follow-up period were excluded. Only the first event for suicidality was included in the estimation of the incidence rates. However, for falls, fractures, burns, or motor vehicle accidents, multiple events occurring during the follow-up period were included. Subsequent events were classified as new events if a subsequent fracture occurred at a different site in the body or at the same site after more than 365 days following the first fracture, ${ }^{17}$ and for motor vehicle accident and burns if the diagnosis codes occurred at least 7 days after the first events. We evaluated health care utilization by enumerating the overall, epilepsy-related and non-epilepsy-related numbers of inpatient (hospitalization) and ED visits during the follow-up period. Epilepsy-specific visits were defined as visits with the diagnosis for epilepsy (345.xx or 780.39 ) as a primary $(\mathrm{Dx} 1)$ diagnosis.

To compare outcomes in treated and untreated persons, follow-up began with the individual's initial AED treatment for treated persons, and a matched date with a health care visit for untreated persons, to a censoring date: at the end of the study period, end of enrollment in the insurance plan, or the first occurrence of suicidality (when applicable).

\section{Statistical analyses}

Descriptive analyses were used for the baseline characteristics. Continuous variables were described using mean, standard deviation, median, and quartiles. Categorical variables were described using frequencies and percentages. The time from a new epilepsy diagnosis to AED treatment was analyzed using the Kaplan-Meier method. The log-rank test was used to test the difference in time to treatment by age $(<17$ vs $\geq 17$ years [i.e., children and adolescents vs adults]), sex (male vs female), and payer type (Commercial/Medicare vs Medicaid). For the comparison of outcomes between treated and untreated persons, controlling for confounding was performed using the high-dimensional propensity score model with inverse probability of treatment weights. ${ }^{18}$ Graphical displays (e.g., box plots) and descriptive statistics were used to assess the distribution of the stabilized weights. The balance and distribution of the baseline characteristics of the cohorts were assessed using standardized mean differences of each covariate across the cohorts. The incidence (event) rates were calculated as the total number of new medical events or health visits during the follow-up period divided by the total person-years of follow-up. The person time for each person was calculated as the total number of days of followup from the index date to the censoring date. Crude and adjusted incidence/event rates and incidence/event rate ratios (IRRs) were computed using the negative binomial model. However, if the negative binomial model did not converge, the analysis was performed using the Poisson regression model. For outcomes with multiple events, the generalized estimating equation Poisson regression model was used to adjust for correlation within individuals. Analyses were conducted using SAS version 9.3 (SAS Institute Inc., Cary, NC).

\section{Data availability}

Original deidentified data used in this analysis were obtained from and are the property of International Business Machines Corporation as successor in interest to Truven Health Analytics LLC by merger/operation of law ("IBM") and IQVIA. 
Figure 1 Primary study: Kaplan-Meier estimate of time to antiepileptic drug treatment for persons with epilepsy
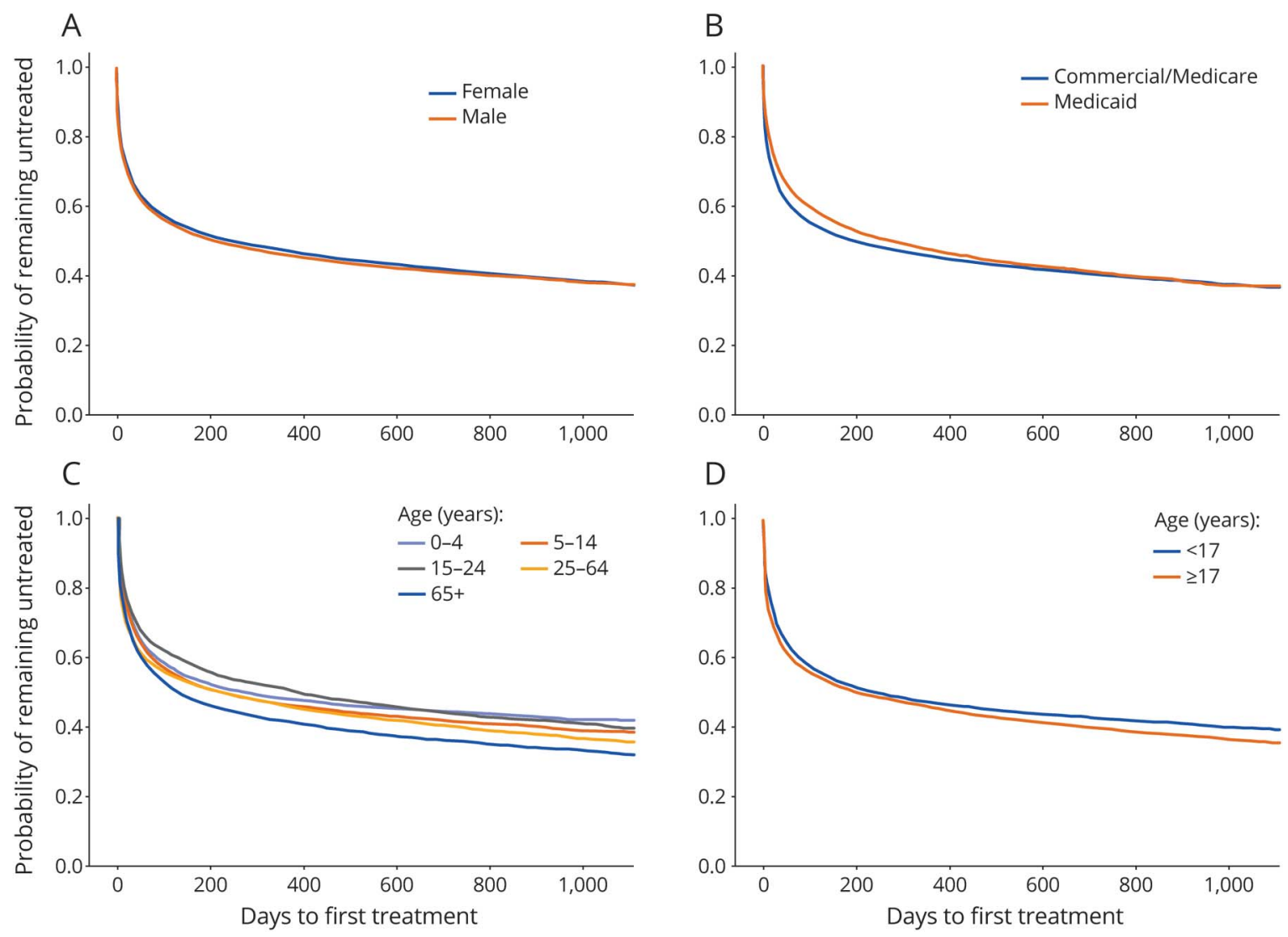

Population stratified by (A) sex, (B) payer type, (C) age group (0-4 years, 5-14 years, 15-24 years, 25-64 years, $65+$ years), and (D) age (<17 years vs 17 years and older).

IBM provided UCB Pharma with the raw data, which were used to create the analytic files for the study. If a third party desires access to the analytic files derived from the MarketScan source data, a third-party use agreement must be executed by the third party, UCB Pharma, and IBM, and access fees may apply. Any third party desiring access to the raw data that were used to generate the analytical files should contact IBM directly regarding the possibility of licensing the data for the appropriate license fees. Data for IQVIA has the analytic files for the study, however UCB Pharma owns the rights. UCB Pharma will make the analytic files available to any researcher who requests them from UCB Pharma for noncommercial purposes after obtaining the necessary approval for third party access for UCB Pharma and IQVIA. Any researcher requiring access to the raw data from IQVIA that were used to generate the analytical files from can access the data directly through a license agreement, including the payment of appropriate license fees, between that third party and IQVIA. Researchers interested in accessing the IQVIA analytical data files should contact Linda Kalilani (Linda.Kalilani@ ucb.com). Researchers interested in accessing the raw data that were used to generate the analytical files for the MarketScan data should contact Jim Robbins (Robbins@ us.ibm.com). Researchers interested in accessing the raw data that were used to generate the analytical files for the validation study should contact IQVIA (William Grochowski,WGrochowski@us.imshealth.com).

\section{Results}

\section{Study population}

Of the 655,858 persons with at least 1 diagnosis code of epilepsy who were identified during the study period in the Truven Health MarketScan databases, a total of 59,970 persons $(9.1 \%)$ were determined to have newly diagnosed epilepsy (45,914 in the Commercial/Medicare database and 14,056 in the Medicaid database) and were selected as eligible for the study after fulfilling all of the inclusion criteria (the following were sequentially excluded: 456,778 [69.6\%] because of lack of continuous coverage during baseline; 102,853 [15.7\%] because of an ICD-9-CM code of 345.xx or 780.39 during baseline; 34,044 [5.2\%] because of a pharmacy claim for an AED during baseline; and 2,213 [0.3\%] because of having $<30$ days of follow-up from the index date). Those persons in the Medicaid population were mostly younger than 17 years of age $(69.0 \%$ vs $25.6 \%$ for the Commercial/ 
Figure 2 Primary study: Percentage of persons with epilepsy who were untreated, by epilepsy case definition

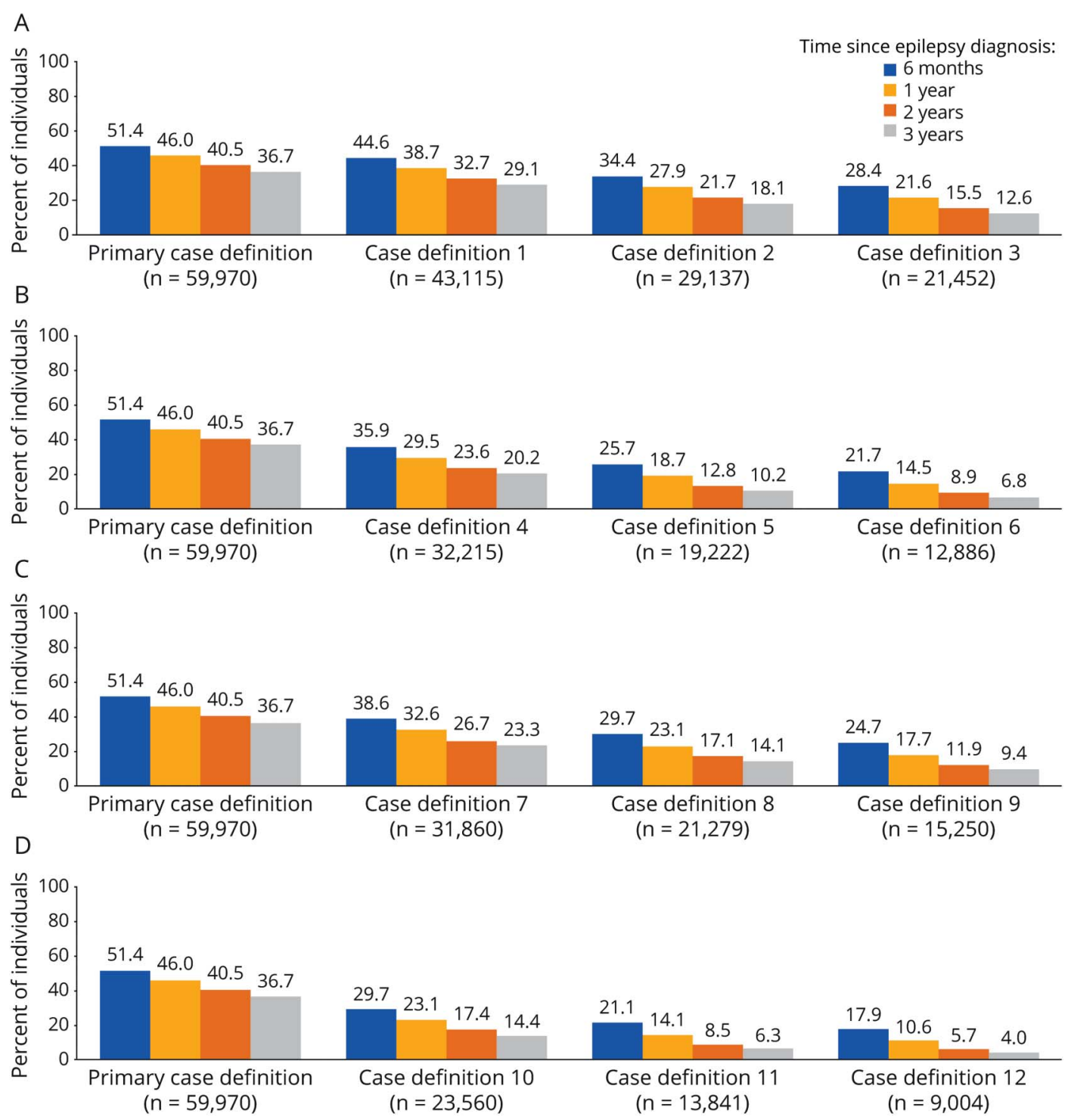

(A) Varying the number of ICD-9-CM codes from 2 to 4; (B) requiring $\geq 30$ days between ICD-9-CM codes; (C) including only the first or principal epilepsy diagnosis; and (D) requiring $\geq 30$ days between epilepsy codes and including only the first or principal diagnosis. ICD-9-CM = International Classification of Diseases, Ninth Revision, Clinical Modification.

Medicare cohort). Overall, the average age was 35.0 years (SD 27.3 years) and $50.5 \%$ were female (table 2 ). The median follow-up time was 443 days (Q1-Q3: 220-760 days).

\section{Treatment with AED after an epilepsy diagnosis}

The Kaplan-Meier estimates for proportions of persons with epilepsy who were untreated with any AED at 6 months, 1 year, and 3 years of follow-up after the date of the index diagnosis were $51.4 \%$ (95\% CI: 51.0\%-51.8\%), 46.0\% (95\% CI: $45.6 \%-46.4 \%$ ), and $36.7 \%$ (95\% CI: $36.1 \%-37.3 \%$ ), respectively. There was no difference in the time to treatment by sex (figure 1A) or payer type (figure 1B). However, there was a difference in the proportion of untreated persons by age, with more of the elderly (65+ years) and fewer of those aged
0 to 4 years receiving treatment (figure $1 \mathrm{C}$ ) and more adults $(17+$ years $)$ vs younger persons ( $<17$ years) receiving treatment (figure 1D).

\section{Sensitivity analyses}

\section{Case definition of epilepsy}

The proportion of persons who did not receive AED treatment varied by the case definition of epilepsy. The percentage of untreated persons decreased as the number of ICD-9 codes required for an epilepsy diagnosis increased (figure $2 \mathrm{~A}$ ). Increasing the minimum required number of days between the ICD-9 codes of epilepsy from 1 to 30 days decreased the proportion of persons with epilepsy who were untreated (figure $2 \mathrm{~A}$ vs figure $2 \mathrm{~B}$ ). Limiting the case definition of 
Table 3 Characteristics among treated and untreated persons

\begin{tabular}{|c|c|c|c|c|}
\hline \multirow[b]{2}{*}{ Population characteristics } & \multicolumn{2}{|c|}{ With condition/characteristic } & \multicolumn{2}{|c|}{ Without condition/characteristic } \\
\hline & No., baseline & $\begin{array}{l}\% \text { Untreated } \\
(95 \% \mathrm{Cl}) \text { at } 3 \text { y }\end{array}$ & No., baseline & $\begin{array}{l}\% \text { Untreated } \\
(95 \% \mathrm{Cl}) \text { at } 3 \text { y }\end{array}$ \\
\hline \multicolumn{5}{|l|}{ Medical condition } \\
\hline Syncope & 5,801 & $37.1(35.3-38.8)$ & 54,169 & $36.6(36.0-37.2)$ \\
\hline Febrile seizures & 524 & $49.0(43.0-54.7)$ & 59,446 & $36.6(36.0-37.2)$ \\
\hline Migraine & 1,621 & $34.0(30.2-37.9)$ & 58,349 & $36.8(36.2-37.3)$ \\
\hline Orthostatic hypotension & 346 & $35.4(28.9-42.0)$ & 59,624 & $36.7(36.1-37.3)$ \\
\hline Alternating hemiplegia & 401 & $21.0(16.4-25.9)$ & 59,569 & $36.8(36.2-37.4)$ \\
\hline Panic disorders & 310 & $41.3(34.6-47.9)$ & 59,660 & $36.7(36.1-37.2)$ \\
\hline TIAs & 2,114 & $27.6(24.7-30.6)$ & 57,856 & $37.1(36.5-37.6)$ \\
\hline Hypoglycemia & 398 & $40.9(34.7-47.1)$ & 59,572 & $36.7(36.1-37.2)$ \\
\hline Vertigo & 3,526 & $37.8(35.4-40.1)$ & 56,444 & $36.6(36.0-37.2)$ \\
\hline Any medical condition & 12,736 & $36.3(35.1-37.5)$ & 47,234 & $36.8(36.1-37.4)$ \\
\hline \multicolumn{5}{|l|}{ Conditions of special interest } \\
\hline Women of childbearing age (15-49y) & 10,932 & $38.6(37.2-40.0)$ & 49,038 & $36.3(35.7-36.9)$ \\
\hline Elderly patients ( $\geq 65$ y) & 10,442 & $31.7(30.3-33.1)$ & 49,528 & $37.7(37.1-38.3)$ \\
\hline \multicolumn{5}{|l|}{ Type of clinic setting at diagnosis } \\
\hline Emergency department & 32,176 & $28.7(27.9-29.5)$ & 27,794 & $45.7(44.9-46.6)$ \\
\hline Hospital & 2,085 & $26.2(23.7-28.7)$ & 57,885 & $37.1(36.5-37.6)$ \\
\hline Outpatient visit & 25,709 & $47.3(46.5-48.2)$ & 34,261 & $28.6(27.8-29.3)$ \\
\hline \multicolumn{5}{|l|}{ Specialty of diagnosis physician } \\
\hline Neurologist & 17,690 & $33.6(32.7-34.6)$ & 42,280 & $38.0(37.3-38.7)$ \\
\hline
\end{tabular}

Abbreviation: $\mathrm{Cl}$ = confidence interval; $\mathrm{TIAs}=$ transient ischemic attacks .

epilepsy to the first or principal diagnosis also decreased the percentage of persons who were untreated (figure $2 \mathrm{~A}$ vs figure $2 \mathrm{C}$ ). Changing the minimum number of days allowed between the ICD-9 codes decreased the percentage of untreated persons slightly more than limiting the diagnosis to first or principal diagnosis (figure $2 \mathrm{~B}$ vs figure $2 \mathrm{C}$ ). Combining all factors (number of ICD-9 codes, the minimum time between codes, and limiting the diagnosis to the first or principal diagnosis) resulted in a marked decrease in the percentage of untreated persons with the most stringent criteria (case definition 12) having the lowest percentage of untreated persons (figure 2D). However, even with the most stringent criterion (case definition 12), 17.9\% (95\% CI: $17.1 \%-18.7 \%$ ) of persons newly diagnosed with epilepsy had received no AED prescription within 6 months after the diagnosis.

\section{Person characteristics and diagnostic setting}

Excluding persons who had diagnosis codes of medical conditions that present with symptoms that may be confused with epilepsy during the baseline period did not have a notable effect on the percentage of persons who remained untreated with an AED after an epilepsy diagnosis (table 3). Compared with the rest of the untreated population, there were fewer elderly (31.7\%, 95\% CI: $30.3 \%-33.1 \%$ vs $37.7 \%$, $95 \%$ CI: $37.1 \%-38.3 \%)$ but slightly more women of childbearing age who were untreated $(38.6 \%$, 95\% CI: $37.2 \%-40.0 \%$ vs $36.3 \%$, 95\% CI: $35.7 \%-36.9 \%)$. There were more persons who were untreated who were diagnosed at an outpatient visit (47.3\%, 95\% CI: $46.5 \%-48.2 \%)$ vs a hospitalization $(26.2 \%, 95 \%$ CI: $23.7 \%-28.7 \%)$ or ED visit (28.7\%, $95 \%$ CI: $27.9 \%-29.5 \%)$. There was a significant proportion of persons who did not receive AED treatment even though epilepsy was diagnosed by a neurologist (33.6\%, 95\% CI: $32.7 \%-34.6 \%)$. This was slightly less than the proportion of untreated persons who were diagnosed by physicians in other specialties (38.0\%, $95 \%$ CI: $37.3 \%-38.7 \%)$.

\section{PharMetrics Plus validation study results}

A total of 31,560 persons with a new diagnosis of epilepsy were identified in the PharMetrics Plus database. Of these, 17,842 persons (56.5\%) were linked to the LRx database: 17,172 (54.4\%) without an AED prescription during baseline 
Figure 3 Validation study: Kaplan-Meier estimate of time to antiepileptic drug treatment for persons with epilepsy
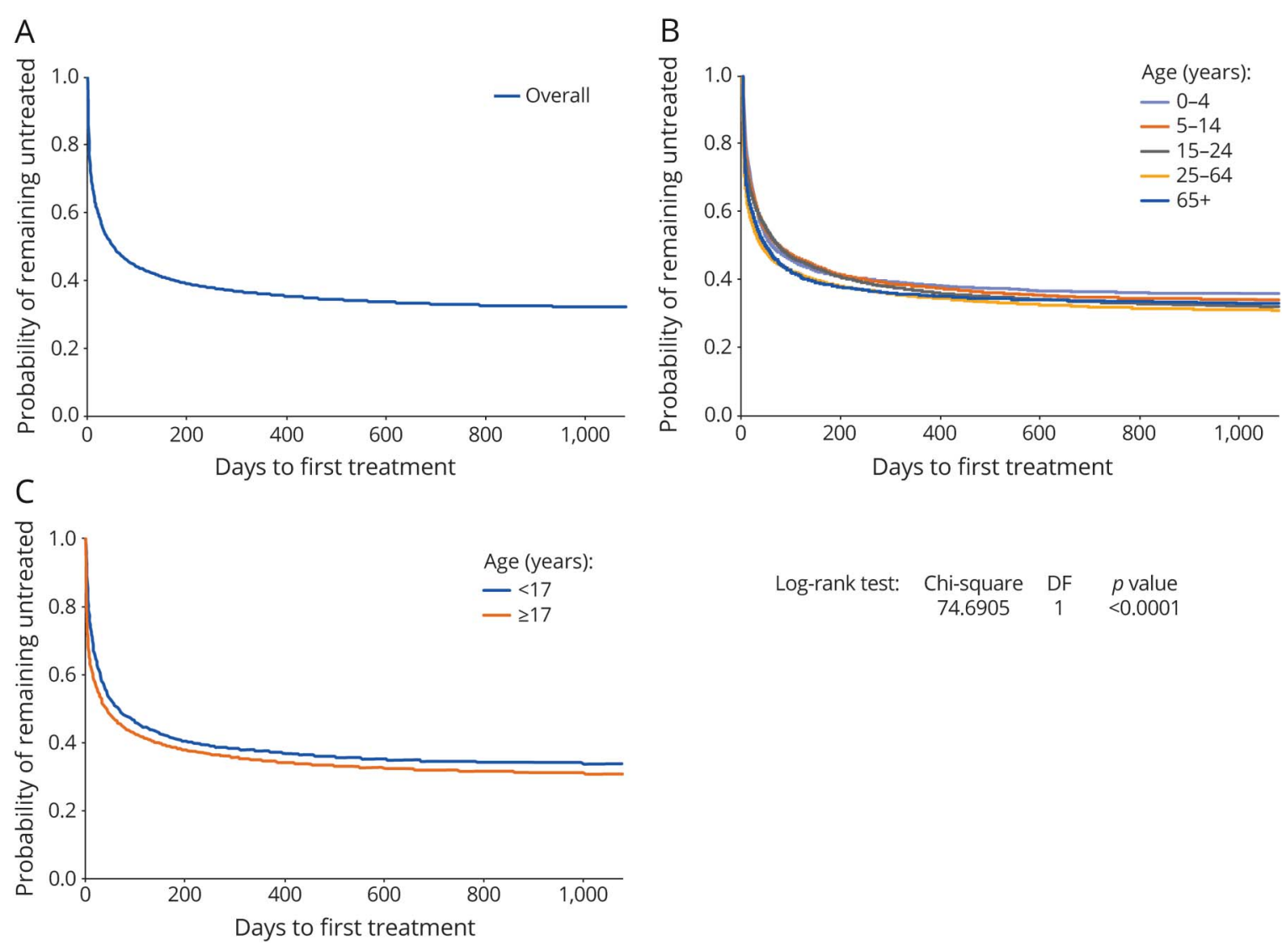

A) Overall population ( $N=30,890)$; and stratified by (B) age group ( $0-4$ years, 5-14 years, 15-24 years, 25-64 years, 65+ years), and (C) age (<17 years vs 17 years and older). DF = degrees of freedom.

and 670 persons $(2.1 \%)$ with an AED prescription during baseline; the latter were excluded, yielding a total of 30,890 incident cases. There were no major differences in the baseline characteristics between persons who were linked and were not linked to the LRx database. The mean age for the study population was 33.3 (29.8 SD) years and there was an equal distribution by sex (female, $48.7 \%$ ). Overall, $31.8 \%$ of the persons remained untreated for up to 3 years of follow-up (figure 3A). There was a difference in time to treatment initiation by age, with fewer persons aged 0 to 4 years receiving treatment (figure 3B), and more adults (17+ years) vs younger persons ( $<17$ years) receiving treatment (figure $3 \mathrm{C}$ ).

\section{Outcomes in treated and untreated persons with epilepsy}

Persons who did not receive any AED treatment for up to 3 years following a new diagnosis of epilepsy had an increased risk of having medical events associated with epilepsy, including burns (adjusted IRR 1.5, 95\% CI: 1.0-2.3), falls (adjusted IRR 1.2, 95\% CI: 1.1-1.4), fractures (adjusted IRR 1.2, 95\% CI: 1.1-1.3), motor vehicle accidents (adjusted IRR 1.6, 95\% CI: 1.3-1.9), and suicidality (adjusted IRR 1.7, 95\% CI: 1.6-1.8) (table 4). Persons who were untreated had higher health care utilization compared with persons who received AED treatment, including hospitalizations (adjusted IRR 2.3, 95\% CI: 2.2-2.3) and ED visits (adjusted IRR 2.8, 95\% CI: 2.7-2.9) (table 4).

\section{Discussion}

Of the 59,970 incident epilepsy cases in our primary study, $51.4 \%$ and $36.7 \%$ remained untreated with an AED at 6 months and 3 years, respectively, after diagnosis. Sensitivity analyses using more stringent criteria to define an epilepsy diagnosis and excluding persons with medical conditions that present with symptoms similar to epilepsy, still showed a high proportion of untreated persons with epilepsy. For example, the proportion of persons untreated at 1 year ranged as follows: $51.4 \%-28.4 \%$ after the number of epilepsy diagnosis codes were increased; $51.4 \%-21.7 \%$ when the time between codes was increased; $51.4 \%-24.7 \%$ when the epilepsy diagnosis was restricted to the principal code; $51.4 \%-17.9 \%$ after increasing the number of epilepsy codes, time between codes, and limiting epilepsy to the principal code; and $36.6 \%-37.3 \%$ when excluding specific medical conditions. Furthermore, the high proportion of untreated persons was 
Table 4 Incidence rates of select medical events in persons with epilepsy who were treated or untreated with antiepileptic drugs for up to 3 years after diagnosis

\begin{tabular}{|c|c|c|c|c|c|c|}
\hline & \multicolumn{2}{|c|}{ Treated persons with epilepsy } & \multicolumn{2}{|c|}{$\begin{array}{l}\text { Untreated persons } \\
\text { with epilepsy }\end{array}$} & \multirow{2}{*}{$\begin{array}{l}\text { Crude incidence } \\
\text { rate ratio }{ }^{\mathrm{a}}(95 \% \mathrm{Cl})\end{array}$} & \multirow{2}{*}{$\begin{array}{l}\text { Adjusted incidenc } \\
\text { rate ratio }(95 \% \mathrm{Cl})\end{array}$} \\
\hline & No. of events & Person-years & No. of events & Person-years & & \\
\hline \multicolumn{7}{|l|}{ Medical event } \\
\hline Any medical event & 7,432 & $49,732.7$ & 6,917 & $43,954.2$ & $1.1(1.0-1.1)$ & $1.2(1.2-1.3)$ \\
\hline Burns & 375 & $49,867.1$ & 405 & $44,078.0$ & $1.2(0.9-1.6)$ & $1.5(1.0-2.3)$ \\
\hline Falls & 3,181 & $49,809.4$ & 2,914 & $44,027.6$ & $1.0(1.0-1.1)$ & $1.2(1.1-1.4)$ \\
\hline Fractures & 4,094 & $49,792.4$ & 3,744 & $44,013.5$ & $1.0(1.0-1.1)$ & $1.2(1.1-1.3)$ \\
\hline Motor vehicle accidents & 452 & $49,865.7$ & 522 & $44,075.9$ & $1.3(1.1-1.6)$ & $1.6(1.3-1.9)$ \\
\hline Suicidality & 85 & $49,716.5$ & 130 & $43,908.6$ & $1.7(1.6-1.8)$ & $1.7(1.6-1.8)$ \\
\hline \multicolumn{7}{|l|}{ Type of health care utilization } \\
\hline \multicolumn{7}{|l|}{ Hospitalizations } \\
\hline All visits & 11,466 & $38,937.2$ & 10,861 & $32,369.8$ & $1.3(1.2-1.3)$ & $2.3(2.2-2.3)$ \\
\hline Non-epilepsy-related & 9,222 & $41,406.1$ & 9,230 & $34,440.0$ & $1.3(1.3-1.4)$ & $2.2(2.1-2.3)$ \\
\hline Epilepsy-related & 3,575 & $46,347.1$ & 2,660 & $41,127.2$ & $0.8(0.8-0.9)$ & $1.2(1.1-1.3)$ \\
\hline \multicolumn{7}{|l|}{ ED visits } \\
\hline All visits & 20,506 & $28,707.9$ & 19,502 & $22,659.5$ & $2.4(2.3-2.4)$ & $2.8(2.7-2.9)$ \\
\hline Non-epilepsy-related & 18,334 & $31,406.5$ & 18,710 & $23,661.8$ & $2.7(2.6-2.8)$ & $3.2(3.1-3.3)$ \\
\hline Epilepsy-related & 5,470 & $44,047.4$ & 2,170 & $41,894.6$ & $0.4(0.3-0.4)$ & $0.4(0.4-0.4)$ \\
\hline
\end{tabular}

Abbreviations: $\mathrm{Cl}$ = confidence interval; $\mathrm{ED}$ = emergency department.

${ }^{a}$ Incidence rate ratio was defined as the incidence rate in untreated persons divided by the incidence rate in treated persons.

${ }^{\mathrm{b}}$ Adjusted using a high-dimensional propensity score model.

confirmed in the validation study, which used a different database. From this database, we found that $31.8 \%$ of incident epilepsy cases remained untreated 3 years after diagnosis. There are no previous studies in the US measuring this type of treatment gap-absence of AED treatment after a diagnosis of epilepsy. Previous studies have reported only an estimated treatment gap in persons with prevalent epilepsy: a $10 \%$ gap among prevalent epilepsy cases was estimated from a systematic literature review. ${ }^{9}$ In a survey study that evaluated use of AEDs in the previous month, $51.2 \%, 6.9 \%$, and $16.1 \%$ of persons with a history of epilepsy, active epilepsy, and any seizure in the past month, respectively, were not receiving an AED. ${ }^{15}$ These results indicate that the treatment gap in persons with epilepsy is not only present in developing countries ${ }^{9}$ but also occurs in developed countries.

There are several factors that could have contributed to the high percentage of untreated persons with epilepsy. First, it is possible that some of them were misclassified as having epilepsy even though validated algorithms were used that have been reported to have high sensitivity and specificity in identifying persons with epilepsy in administrative databases. ${ }^{19}$ However, despite sensitivity analyses using more stringent criteria (i.e., more epilepsy diagnostic codes [from $\geq 2$ to $\geq 4$ ], more days between diagnostic codes [from $\geq 1$ to $\geq 30$ ], and restriction of the epilepsy codes to a principal diagnosis), a high percentage of the newly diagnosed persons remained untreated for extended periods of time. It should be noted that the proportion untreated diminished substantially with increasing number of epilepsy diagnoses, which may in part reflect a higher positive predictive value in the case definition ${ }^{19}$ or a less representative subset including a high proportion of persons with more frequent or severe seizures whose need for AED treatment is greatest. In addition, excluding medical conditions that could resemble epilepsy in the analyses did not have a notable effect on the percentage of persons who remained untreated. Further studies linking claims to electronic medical record databases with searches of individual records would be needed to obtain a better estimate of the proportion of persons who were misclassified as having epilepsy (i.e., false-positive diagnoses of epilepsy). There is a recent study comparing the performance of several previously published algorithms for the diagnosis of epilepsy from claims data with a chart review of patients from a separate electronic database. ${ }^{20}$ The algorithm most similar to the one we used is described in reference 16 because it utilized only diagnosis codes 
without a requirement for a prescription fill. In comparison with the chart review, this algorithm had a specificity of $83 \%$. In summary, we believe that most of our patients had a valid diagnosis of epilepsy and that the treatment gap cannot be explained completely by false-positive diagnoses of epilepsy.

It is also possible that the claims databases may not capture all of the treatment information, especially for persons who do not have insurance coverage for prescriptions, or who have dual insurance coverage with some claims not included in the database. Thus, our analysis was restricted to persons who had both medical and prescription insurance coverage. Most older persons (65+ years) in the US are covered by Medicare insurance, and it was anticipated that the databases would not include information on prescriptions that were covered entirely by Medicare. However, our study found that the percentage of untreated persons among older persons was lower than among other age groups. These factors indicate that the database contained most of the treatment information for the persons. Persons aged $>65$ years had the shortest time to treatment compared with other age groups, which may reflect higher treatment-seeking behavior ${ }^{21}$ or diagnosis acceptance. ${ }^{22}$ The validation study was designed to address this situation by linking the PharMetrics Plus claims database to a larger prescription claims database with prescriptions paid with cash, to ensure that information on all prescriptions was available. Increased access to prescription information resulted in only $3.8 \%$ additional AED prescriptions, and a gap in AED treatment persisted.

Another possible limitation of our data is that claims data reflect fulfilled prescriptions, and it is possible that persons chose not to fill their prescription despite their health care provider recommending treatment, and thus were untreated. A prospective study of a primary care network found that one-third of all prescriptions for a variety of diagnoses were not filled. ${ }^{23}$ It should also be noted that the database does not include information on adherence; therefore, the treatment gap may be higher than estimated as some persons who filled their prescriptions did not take the medication.

The treatment gap could also reflect a conservative approach by clinicians, ${ }^{24}$ personal decision not to take medication, or use of alternative approaches to treatment such as lifestyle changes or use of nonprescription remedies. ${ }^{25}$ Physicians may decide not to treat if patients have very low seizure frequency, such as in benign rolandic epilepsy. ${ }^{26}$ Treatment with AEDs may be considered after a first unprovoked seizure if the probability of recurrence is very high (estimated at $57 \%$ at 1 year), ${ }^{27}$ and is recommended after an epilepsy diagnosis, ${ }^{5}$ to reduce the risk of seizure recurrence. The decision to initiate AED treatment must take into account factors including seizure type and frequency; an individual's characteristics, comorbidities, comedications, lifestyle, and preference; and
AED safety and efficacy. ${ }^{5}$ The sensitivity analysis indicated that women of childbearing age were more likely to be untreated, perhaps a reflection of concern with pregnancyrelated issues such as teratogenicity. ${ }^{28}$

We also found that persons who were diagnosed during an outpatient visit $(47.3 \%)$ were less likely to be treated than those who were diagnosed during an ED visit $(28.7 \%)$ or hospitalization $(26.2 \%)$. This may indicate persons diagnosed during an $\mathrm{ED}$ visit or hospitalization have severe disease compared with persons seen in an outpatient setting.

Cost and type of insurance coverage could be another reason for not initiating treatment. Medicaid recipients typically have few specialist choices and may encounter formulary limitations, which may impede treatment. ${ }^{29}$ Our study found a higher percentage of untreated persons among those younger than 17 years of age compared with persons 17 years and older. About $43 \%$ of this age group have Medicaid insurance in our cohort, which may reflect limited prescription access and other treatment challenges among young persons receiving Medicaid. It could also involve factors of seizure type ("benign" epilepsy syndromes) or reluctance to treat children by parent or physicians. Our data also suggest that specialist care is associated with higher rates of treatment, as noted in other studies. ${ }^{13}$

The consequences of untreated epilepsy range from cognitive impairment, diminished quality of life, and higher health care resource use and costs, to increased rates of mortality. ${ }^{30} \mathrm{Ad}-$ herence to AED therapy reduces mortality compared with nonadherence. ${ }^{31}$ In our study, health outcomes in treated vs untreated cohorts were compared, as well as the effect of AED treatment on resource use. A $20 \%$ increased risk of any medical event (ranging from 20\% for falls or fractures to $70 \%$ for suicidality) was found among untreated vs treated persons with epilepsy. Compared with treated persons, untreated persons incurred a greater than 2-fold increased risk of hospitalizations and ED visits, suggesting that untreated epilepsy results in medical events necessitating increased use of health care resources. Even though the risk of all-cause ED visits was higher in untreated than treated persons, the risk of epilepsyrelated ED visits was lower. This could be because the primary diagnosis for the visits was not coded for epilepsy even if it was the main underlying reason for the visit. For example, if a person had a burn as a result of loss of consciousness during a seizure, the primary diagnosis for that visit may have been coded as burns and epilepsy coded in the other fields of diagnosis.

Our study is limited by factors associated with retrospective database analyses. Claims databases are subject to misclassification, upcoding of diagnosis, and errant, missing, or incomplete information. Persons may have sought alternative modes of treatment not captured in the database. Furthermore, study results may not be generalizable because the study population is limited to persons with 
commercial, Medicare supplemental, or Medicaid insurance, and therefore, may not be representative of the entire US population, including noninsured persons. There is also a possibility for residual confounding when comparing outcomes in persons who were treated or untreated for epilepsy.

Among incident epilepsy cases, over one-third remained untreated with any AED for at least 6 months and up to 3 years after diagnosis. A treatment gap persisted after conducting rigorous sensitivity analyses and a validation study in a different database. This gap is particularly worrisome given the effect of delayed treatment on patient outcomes and resource use. Further studies using enriched databases and individual chart reviews are needed to verify the magnitude of this treatment gap and to understand the reasons for it. However, individual chart reviews at tertiary epilepsy centers would not be representative of the US population with incident epilepsy. Our study strongly suggests that the "treatment gap" in epilepsy is not a phenomenon confined to developing countries or to underserved populations, ${ }^{12-14}$ but encompasses many persons with a valid diagnosis of epilepsy and who should have access to AEDs, but for various reasons may not be obtaining them.

\section{Acknowledgment}

The authors acknowledge the contributions of Helen Ysak, PharmD (UCB Pharma, Smyrna, GA), for publication coordination, and Lynne Isbell, $\mathrm{PhD}, \mathrm{CMPP}$ (Evidence Scientific Solutions, Philadelphia, PA) for assistance in collating/incorporating author comments, editing, and formatting, which was funded by UCB Pharma.

\section{Study funding}

This study was sponsored by UCB Pharma.

\section{Disclosure}

L. Kalilani is an employee of UCB Pharma. E. Faught received compensation for consulting or research data review board service from Eisai, UCB Pharma, and SK Life Science, and research funding via Emory University from Brain Sentinel, UCB Pharma, and the University of Alabama at Birmingham. $\mathrm{H}$. Kim received funding for research activities from UCB Pharma. C. Burudpakdee is an employee of IQVIA, which received compensation from UCB Pharma. A. Seetasith is an employee of IQVIA, which received compensation from UCB Pharma. S. Laranjo was an employee of UCB Pharma at the time of this study. D. Friesen is an independent consulting analyst of UCB Pharma. K. Haeffs is an employee of UCB Pharma. V. Kiri is an independent consulting analyst of UCB Pharma. D. Thurman received compensation for consulting and research funding from UCB Pharma. Go to Neurology. org/ $\mathrm{N}$ for full disclosures.

\section{Publication history}

Received by Neurology September 11, 2018. Accepted in final form January 11, 2019.

\section{Appendix Authors}

\begin{tabular}{|c|c|c|c|}
\hline Name & Location & Role & Contribution \\
\hline $\begin{array}{l}\text { Linda Kalilani, } \\
\text { PhD }\end{array}$ & $\begin{array}{l}\text { UCB Pharma, } \\
\text { Raleigh, NC }\end{array}$ & Author & $\begin{array}{l}\text { Design and } \\
\text { conceptualization of } \\
\text { study, analysis and } \\
\text { interpretation of data, } \\
\text { drafting and revising } \\
\text { manuscript for } \\
\text { intellectual content }\end{array}$ \\
\hline
\end{tabular}

\begin{tabular}{|c|c|c|c|}
\hline $\begin{array}{l}\text { Edward } \\
\text { Faught, MD }\end{array}$ & $\begin{array}{l}\text { Emory University } \\
\text { School of } \\
\text { Medicine, } \\
\text { Atlanta, GA }\end{array}$ & Author & $\begin{array}{l}\text { Design and } \\
\text { conceptualization of } \\
\text { study, interpretation of } \\
\text { data, drafting and } \\
\text { revising manuscript for } \\
\text { intellectual content }\end{array}$ \\
\hline $\begin{array}{l}\text { Hyunmi Kim, } \\
\text { MD, PhD }\end{array}$ & $\begin{array}{l}\text { Stanford } \\
\text { University } \\
\text { School of } \\
\text { Medicine, Palo } \\
\text { Alto, CA }\end{array}$ & Author & $\begin{array}{l}\text { Design and } \\
\text { conceptualization of } \\
\text { study, interpretation of } \\
\text { data, drafting and } \\
\text { revising manuscript for } \\
\text { intellectual content }\end{array}$ \\
\hline $\begin{array}{l}\text { Chakkarin } \\
\text { Burudpakdee, } \\
\text { PharmD }\end{array}$ & IQVIA, Fairfax, VA & Author & $\begin{array}{l}\text { Analysis and } \\
\text { interpretation of data, } \\
\text { revising manuscript for } \\
\text { intellectual content }\end{array}$ \\
\hline $\begin{array}{l}\text { Arpamas } \\
\text { Seetasith, PhD }\end{array}$ & IQVIA, Fairfax, VA & Author & $\begin{array}{l}\text { Analysis and } \\
\text { interpretation of data }\end{array}$ \\
\hline $\begin{array}{l}\text { Scott Laranjo, } \\
\text { MBA }\end{array}$ & $\begin{array}{l}\text { UCB Pharma, } \\
\text { Smyrna, GA }\end{array}$ & Author & $\begin{array}{l}\text { Design and } \\
\text { conceptualization of } \\
\text { study, interpretation of } \\
\text { data, revising } \\
\text { manuscript for } \\
\text { intellectual content }\end{array}$ \\
\hline $\begin{array}{l}\text { David Friesen, } \\
\text { BSc }\end{array}$ & $\begin{array}{l}\text { UCB Pharma, } \\
\text { Ascot, Berkshire, } \\
\text { UK }\end{array}$ & Author & Analysis of data \\
\hline $\begin{array}{l}\text { Kathrin } \\
\text { Haeffs, PhD }\end{array}$ & $\begin{array}{l}\text { UCB Pharma, } \\
\text { Monheim am } \\
\text { Rhein, Germany }\end{array}$ & Author & $\begin{array}{l}\text { Analysis and } \\
\text { interpretation of data, } \\
\text { revising manuscript for } \\
\text { intellectual content }\end{array}$ \\
\hline $\begin{array}{l}\text { Victor Kiri, } \\
\text { PhD, MPH }\end{array}$ & $\begin{array}{l}\text { FV \& JK } \\
\text { Consulting Ltd., } \\
\text { Guildford, } \\
\text { Surrey, UK }\end{array}$ & Author & $\begin{array}{l}\text { Analysis and } \\
\text { interpretation of data, } \\
\text { revising manuscript for } \\
\text { intellectual content }\end{array}$ \\
\hline $\begin{array}{l}\text { David J. } \\
\text { Thurman, MD, } \\
\text { MPH }\end{array}$ & $\begin{array}{l}\text { Emory University } \\
\text { School of } \\
\text { Medicine, } \\
\text { Atlanta, GA }\end{array}$ & Author & $\begin{array}{l}\text { Design and } \\
\text { conceptualization of } \\
\text { study, interpretation of } \\
\text { data, drafting and } \\
\text { revising manuscript for } \\
\text { intellectual content }\end{array}$ \\
\hline
\end{tabular}

\section{References}

1. de Boer HM, Mula M, Sander JW. The global burden and stigma of epilepsy. Epilepsy Behav 2008;12:540-546.

2. Thurman DJ, Kobau R, Luo YH, Helmers SL, Zack MM. Health-care access among adults with epilepsy: the U.S. National Health Interview Survey, 2010 and 2013. Epilepsy Behav 2016;55:184-188.

3. Levira F, Thurman DJ, Sander JW, et al. Premature mortality of epilepsy in low- and middle-income countries: a systematic review from the Mortality Task Force of the International League Against Epilepsy. Epilepsia 2017;58:6-16.

4. Thurman DJ, Logroscino G, Beghi E, et al. The burden of premature mortality of epilepsy in high-income countries: a systematic review from the Mortality Task Force of the International League Against Epilepsy. Epilepsia 2017;58:17-26.

5. National Institute for Health and Care Excellence. Epilepsies: diagnosis and management—clinical guideline [CG137] [online]. Available at: nice.org.uk/guidance/cg137. Accessed February 20, 2018.

6. Sperling MR. The consequences of uncontrolled epilepsy. CNS Spectr 2004;9: 98-101, 106-109. 
7. George J, Kulkarni C, Sarma GRK. Antiepileptic drugs and quality of life in patients with epilepsy: a tertiary care hospital-based study. Value Health Reg Issues 2015;6: $1-6$.

8. Faught E, Helmers S, Thurman D, Kim H, Kalilani L. Patient characteristics and treatment patterns in patients with newly diagnosed epilepsy: a US database analysis. Epilepsy Behav 2018;85:37-44.

9. Meyer AC, Dua T, Ma J, Saxena S, Birbeck G. Global disparities in the epilepsy treatment gap: a systematic review. Bull World Health Organ 2010;88:260-266.

10. Kale R. Global campaign against epilepsy: the treatment gap. Epilepsia 2002;43(suppl 6):31-33.

11. Neligan A, Sander JW. The treatment gap in epilepsy: a global perspective. Epileptology 2013;1:28-30.

12. Mbuba CK, Ngugi AK, Newton CR, Carter JA. The epilepsy treatment gap in developing countries: a systematic review of the magnitude, causes, and intervention strategies. Epilepsia 2008;49:1491-1503.

13. Meyer AC, Dua T, Boscardin WJ, Escarce JJ, Saxena S, Birbeck GL. Critical determinants of the epilepsy treatment gap: a cross-national analysis in resource-limited settings. Epilepsia 2012;53:2178-2185.

14. Baftiu A, Johannessen Landmark C, Nikaj V, Neslein IL, Johannessen SI, Perucca E. Availability of antiepileptic drugs across Europe. Epilepsia 2015;56:e191-e197.

15. Kobau R, Zahran H, Thurman DJ, et al. Epilepsy surveillance among adults-19 states, Behavioral Risk Factor Surveillance System, 2005. MMWR Surveill Summ 2008;57:1-20.

16. Reid AY, St Germaine-Smith C, Liu M, et al. Development and validation of a case definition for epilepsy for use with administrative health data. Epilepsy Res 2012;102: 173-179.

17. Bhandari M, Guyatt GH, Swiontkowski MF, Tornetta P III, Sprague S, Schemitsch EH. A lack of consensus in the assessment of fracture healing among orthopaedic surgeons. J Orthop Trauma 2002;16:562-566.

18. Brookhart MA, Wyss R, Layton JB, Stürmer T. Propensity score methods for confounding control in nonexperimental research. Circ Cardiovasc Qual Outcomes 2013; 6:604-611.
19. Kee VR, Gilchrist B, Granner MA, Sarrazin NR, Carnahan RM. A systematic review of validated methods for identifying seizures, convulsions, or epilepsy using administrative and claims data. Pharmacoepidemiol Drug Saf 2012;21(suppl 1):183-193.

20. Moura LM, Price M, Cole AJ, Hoch DB, Hsu J. Accuracy of claims-based algorithms for epilepsy research: revealing the unseen performance of claims-based studies. Epilepsia 2017;58:683-691.

21. Centers for Disease Control and Prevention (CDC). Epilepsy in adults and access to care-United States, 2010. MMWR Morb Mortal Wkly Rep 2012;61:909-913.

22. Canuet L, Ishii R, Iwase M, et al. Factors associated with impaired quality of life in younger and older adults with epilepsy. Epilepsy Res 2009;83:58-65.

23. Tamblyn R, Eguale T, Huang A, Winslade N, Doran P. The incidence and determinants of primary nonadherence with prescribed medication in primary care: a cohort study. Ann Intern Med 2014;160:441-450.

24. Chadwick D. Starting and stopping treatment for seizures and epilepsy. Epilepsia 2006;47(suppl 1):58-61.

25. Kneen R, Appleton RE. Alternative approaches to conventional antiepileptic drugs in the management of paediatric epilepsy. Arch Dis Child 2006;91:936-941.

26. Mellish LC, Dunkley C, Ferrie CD, Pal DK. Antiepileptic drug treatment of rolandic epilepsy and Panayiotopoulos syndrome: clinical practice survey and clinical trial feasibility. Arch Dis Child 2015;100:62-67.

27. Krumholz A, Shinnar S, French J, Gronseth G, Wiebe S. Evidence-based guideline management of an unprovoked first seizure in adults: report of the Guideline Development Subcommittee of the American Academy of Neurology and the American Epilepsy Society. Neurology 2015;85:1526-1527.

28. Crawford PM. Managing epilepsy in women of childbearing age. Drug Saf 2009;32:293-307.

29. Schiltz NK, Koroukian SM, Singer ME, Love TE, Kaiboriboon K. Disparities in access to specialized epilepsy care. Epilepsy Res 2013;107:172-180.

30. Cardarelli WJ, Smith BJ. The burden of epilepsy to patients and payers. Am J Manag Care 2010;16(12 suppl):S331-S336.

31. Faught E, Duh MS, Weiner JR, Guérin A, Cunnington MC. Nonadherence to antiepileptic drugs and increased mortality: findings from the RANSOM Study. Neurology 2008;71:1572-1578. 


\section{Neurology}

\section{Assessment and effect of a gap between new-onset epilepsy diagnosis and treatment in the US}

Linda Kalilani, Edward Faught, Hyunmi Kim, et al.

Neurology 2019;92;e2197-e2208 Published Online before print April 10, 2019

DOI 10.1212/WNL.0000000000007448

This information is current as of April 10, 2019

\section{Updated Information \& Services}

References

Citations

Subspecialty Collections

Permissions \& Licensing

Reprints including high resolution figures, can be found at: http://n.neurology.org/content/92/19/e2197.full

This article cites 30 articles, 5 of which you can access for free at: http://n.neurology.org/content/92/19/e2197.full\#ref-list-1

This article has been cited by 4 HighWire-hosted articles: http://n.neurology.org/content/92/19/e2197.full\#\#otherarticles

This article, along with others on similar topics, appears in the following collection(s):

All Epilepsy/Seizures

http://n.neurology.org/cgi/collection/all_epilepsy_seizures

All Health Services Research

http://n.neurology.org/cgi/collection/all_health_services_research

Antiepileptic drugs

http://n.neurology.org/cgi/collection/antiepileptic_drugs

Medical care

http://n.neurology.org/cgi/collection/medical_care

Outcome research

http://n.neurology.org/cgi/collection/outcome_research

Information about reproducing this article in parts (figures,tables) or in its entirety can be found online at:

http://www.neurology.org/about/about_the_journal\#permissions

Information about ordering reprints can be found online:

http://n.neurology.org/subscribers/advertise

Neurology ${ }^{\circledR}$ is the official journal of the American Academy of Neurology. Published continuously since 1951, it is now a weekly with 48 issues per year. Copyright Copyright ( 2019 The Author(s). Published by Wolters Kluwer Health, Inc. on behalf of the American Academy of Neurology.. All rights reserved. Print ISSN: 0028-3878. Online ISSN: 1526-632X.

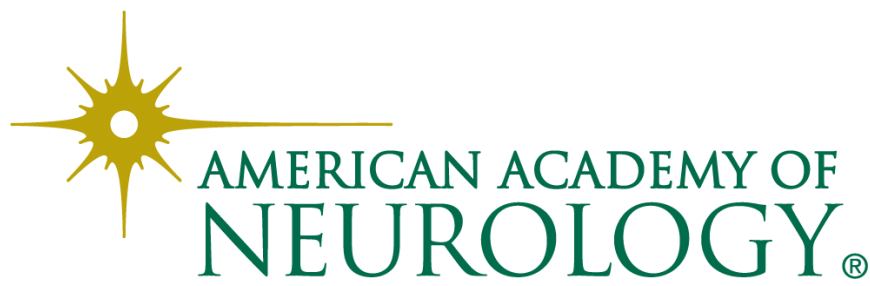

